Guest Editorial, part of a Special Feature on Risk mapping for avian influenza: a social-ecological problem

\title{
Risk Mapping for Avian Influenza: a Social-Ecological Problem
}

\author{
Graeme S. Cumming $^{1}$
}

\begin{abstract}
Pathogen dynamics are inseparable from the broader environmental context in which pathogens occur. Although some pathogens of people are primarily limited to the human population, occurrences of zoonoses and vector-borne diseases are intimately linked to ecosystems. The emergence of these diseases is currently being driven by a variety of influences that include, among other things, changes in the human population, long-distance travel, high-intensity animal-production systems, and anthropogenic modification of ecosystems. Anthropogenic impacts on ecosystems have both direct and indirect (foodweb mediated) effects. Therefore, understanding disease risk for zoonoses is a social-ecological problem. The articles in this special feature focus on risk assessment for avian influenza. They include analyses of the history and epidemiological context of avian influenza; planning and policy issues relating to risk; the roles of biogeography and spatial and temporal variation in driving the movements of potential avian influenza carriers; approaches to quantifying risk; and an assessment of risk-related interactions among people and birds in Vietnamese markets. They differ from the majority of published studies of avian influenza in that they emphasize unknowns and uncertainties in risk mapping and societal responses to avian influenza, rather than concentrating on known or proven facts. From a systems perspective, the different aspects of social-ecological systems that are relevant to the problem of risk mapping can be summarized under the general categories of structural, spatial, and temporal components. I present some examples of relevant system properties, as suggested by this framework, and argue that, ultimately, risk mapping for infectious disease will need to develop a more holistic perspective that includes explicit consideration of the roles of policy, disease management, and feedbacks between ecosystems and societies.
\end{abstract}

Key Words: disease; framework; health; influenza; pathogen; resilience; social-ecological system

\section{INTRODUCTION}

As scientific knowledge about infectious diseases has grown, it has gradually become apparent that the pathogens that cause disease in populations of humans and other animals are not isolated entities. Pathogens exist within a broader environmental context that influences where and when they occur. Explorations of what constitutes the "environmental context" for a pathogen have shown that their occurrences can be influenced by many of the same variables that determine the occurrences of other organisms. These include such diverse influences as abiotic variation, biotic variation, population and community-level processes, ecological interactions, e.g., predation and parasitism, spatiotemporal patterns of habitat use, perturbations, and ecological history (e.g., Dobson and Foufopoulos 2001, Guernier et al. 2004, Tung et al. 2009).

For pathogens of humans, traditional approaches have assumed that the primary context for pathogens is the human population. In this paradigm, understanding disease dynamics is primarily a question of understanding human populations and human behaviors. For example, there is good reason to believe that cyclical patterns of measles outbreaks are primarily caused by predictable changes in the proportion of the human population that has been vaccinated at any one time (e.g., Anderson and May 1983, Agur et al. 1993). Similarly, HIV transmission within human populations is primarily considered to be a function of the number and nature of opportunities for 
sharing body fluids within the human population, including such things as sexual encounters, shared needles or syringes, and blood transfusions (Beyrer 2007).

For many well-established infectious diseases, the analysis of transmission patterns needs to go no further than the human population (e.g., Bessen 2009). However, for new and emerging diseases and for vector-borne diseases, the nature of the problem is different (e.g., Daszak et al. 2001, Carver et al. 2009). Vector-borne diseases are transmitted by animals that are members of broader food webs. In addition, many human pathogens are zoonoses (Woolhouse and Gowtage-Sequeria 2005, Jaffry et al. 2009), meaning that they have been derived from other animals and have crossed the species boundary to become infectious to humans. Examples of known or suspected zoonoses include many pathogens of high concern in modern society, such as HIV, anthrax, ebola, tuberculosis, and some strains of influenza (Jaffry et al. 2009). Zoonoses are not static entities, and their entry into human populations is seldom a unique occurrence. For example, although influenza is a well-established disease, its potential for recombination into novel forms in nonhuman hosts means that it will always have the potential for emergence in new forms.

Recent years have seen the emergence of many new infectious zoonoses in humans and wildlife (Daszak et al. 2000, 2001, Morens et al. 2008, Tee et al. 2009). It is difficult to establish rigorously whether the general trend in infectious disease incidence is one of increase because our detection of pathogens correlates with improvements in surveillance and diagnostic methods (e.g., Mogollon-Pasapera et al. 2009) that are difficult to quantify, but a number of factors appear to be contributing to the emergence of new infectious zoonoses. One of the most obvious of these is the globally increasing human population that offers more genetic variation and higher encounter rates with candidate pathogens (Daszak et al. 2000, Morens et al. 2008). More people exist than at any previous time in the earth's history, and modern transport systems make it possible for a person to travel around the world in a matter of days. Therefore, travel-related infection opportunities for pathogens are steadily increasing (Tatem 2009). The 2009 outbreak of swine flu (H1N1) demonstrated that despite the implementation of standard precautions, a contagious virus can travel from South America to Europe, South Africa, and Australia in a matter of weeks.
Another obvious trend that relates closely to the emergence of infectious zoonoses is the increase in high-intensity animal-production systems that offer numerous opportunities for people to interact with other animals in potentially high-transmission situations (Field 2009). It is possible in today's world for poultry to be caged over ponds in which fish are grown, for fish scraps from these farms to be ground into meal and fed to livestock, and for the bones of these livestock in turn to be fed to poultry and fish in the form of bone meal. Similarly, pigs are classic "mixing vessels" for different viral strains of people and animals (Capua and Alexander 2002) and are frequently fed on poultry manure (e. g., Devendra 2007). Such tight feedback loops among different species and people offer significant opportuities for the emergence of pathogens.

A third important trend is the human modification of ecosystems (Daszak et al. 2001, Tilman and Lehman 2001, Morens et al. 2008). As the human population expands, people are altering ecosystems in a variety of ways. These alterations have both direct and indirect effects (Walsh et al. 1993, Woolhouse and Gowtage-Sequeria 2005). The direct effects derive from the contact of people with pathogens in their native environment. People who are engaged in activities that modify landscape structure, such as tree-felling or farming, may at the same time create "new" habitats for known pathogens and vectors (Walsh et al. 1993). At the same time, as people interact with new habitats, they may encounter novel pathogens to which they have little or no immunity (however, see the perspective provided by Pontier et al. 2009 on this issue). The colonization of Africa, North America, and South America by Europeans provides numerous historical examples of what happens when naive immune systems encounter novel pathogens. The tendency for zoonoses to emerge from novel socialecological interactions continues into recent times with the rise of such pathogens as the Nipah virus (Field 2009).

The indirect consequences of human alteration of ecosystems are harder to tease out than the direct consequences, but they may be equally important. Disease regulation can be regarded as a form of ecosystem service (Ostfeld 2009). Ecosystems regulate disease through several different mechanisms, most of which involve either the reduction of pathogen impacts through blind-ending transmission pathways and host heterogeneity (e.g., Dwyer et al. 1997, Ostfeld 2009), or the removal of 
unhealthy individuals from the system. In particular, predation is a strong selective process that helps reduce the time during which unhealthy animals may infect others. By destroying and fragmenting natural habitats, and through such activities as hunting and the introduction of invasive species, humans are altering the capacity of ecosystems to regulate disease. Biodiversity has been shown to reduce infection levels in natural populations (Altizer et al. 2003, Ostfeld 2009). Alterations to food webs can have unexpected knock-on effects as interspecific interactions change and animal populations are released from trophic constraints (Borer et al. 2009). It has been proposed that, as food webs collapse, upper trophic levels are lost before lower trophic levels (Dobson et al. 2006). This suggestion is supported by empirical data, such as the finding that among South African birds, the diversity of raptors and scavengers is heavily reduced in agricultural areas (Child et al. 2009). At the same time, range expansions of many waterbirds in South Africa, including likely vectors of avian influenza, have occurred through the construction of farm dams (Okes et al. 2008). The disruption of ecosystem processes and the loss of predators from ecosystems, therefore, provide yet more opportunities for infectious diseases to gain a foothold in animal communities, making it increasingly more likely that a given pathogen will come into contact with humans.

Disease ecologists are gradually working toward a framework for the analysis of some of these different ingredients in understanding and quantifying the likelihood of pathogen emergence and spread (Altizer et al. 2003, Kahn 2006, Hoberg et al. 2008). However, the ecology of zoonoses is as much a social and political problem as it is an ecological one. This duality is apparent in attempts to develop risk maps for pathogen occurrences, which provide a convenient focal point for the development of interdisciplinary perspectives on disease.

\section{THE SPECIAL FEATURE}

Many of the factors discussed above are directly relevant to the emergence of new forms of influenza, of which bird flu and swine flu are but two of the most recent examples. Two papers in the feature provide overviews of issues surrounding avian influenza (AI) by respectively reviewing its emergence and current trajectory (Dudley 2008) and addressing the question of how we should approach the assessment of influenza-related risks (Stirling and Scoones 2009).

As Dudley (2008) explains, our ability to accurately assess and map the societal risks associated with avian influenza outbreaks is constrained by some important uncertainties about the ecology and epidemiology of avian influenza viruses in birds and humans. In particular, we lack a solid understanding of the causes of the emergence and persistence of highly pathogenic avian influenza (HPAI) viruses in poultry populations, the interactions between industrial poultry farms and backyard poultry flocks, the potential role of migratory and nomadic bird populations in spreading HPAI viruses, and the potential for wild-bird populations to serve as reservoirs for avian influenza viruses. We also face uncertainties over the efficacy and relevance of different kinds of response, such as vaccination programs in humans and poultry, and the risks associated with different poultry-farming approaches are largely unknown.

Stirling and Scoones (2009) place some of these concerns firmly within the domain of policy and planning. They argue that global policies are based primarily on a particular kind of "incertitude," that of traditional scientific uncertainty. Socialecological systems are also subject to other forms of incertitude, however, including ignorance, ambiguity, and risk. Risk assessment must consider at least three kinds of incertitude: the likelihood of a particular outcome, its potential consequences for society, and the potential consequences of scientific engagement with the problem. Because what eventually happens in any social-ecological system is a result of a set of complex interacting processes, traditional scientific methods may substantially underestimate uncertainty, and hence, risk (see also Clark et al. 2001, Carpenter 2002). Traditional scientific methods may also be less appropriate when questions of ambiguity and ignorance arise. For example, if perceptions of the value of rural poultry differ between health officials and a local community, measures of risk that incorporate poultry values in a cost-benefit equation may give different outcomes depending on which value is used. Stirling and Scoones (2009) argue that broadbased precautionary and participatory approaches may be better suited than classical science to assessing risk, because they offer ways to be more rigorous and complete in the mapping of different framings of a particular problem. As the process by 
which it was formulated can be an important determinant of the success or failure of a given policy (Adger and Jordan 2009), participatory methods may also be more robust than traditional appraisal methods in creating greater accountability for value-laden judgments about the risks of threats like pandemics of avian influenza.

Keeping the history and recent progress of the disease in mind (Dudley 2008), as well as the concerns raised by Stirling and Scoones (2009), the rest of the papers in the feature focus on different ways of obtaining provisional assessments of risk that go beyond simple analyses of wild-bird or poultry dynamics. Peterson and Williams (2008) focus on capturing the details of mechanisms of avian influenza transmission and identify some of the points on which risk mapping can focus. They illustrate current approaches to mapping risk based on three different kinds of data: avian influenza case occurrences, poultry distributions and movements, and migratory bird movements. A detailed example of risk mapping for avian influenza in Europe, using prevalence data, is presented by $\mathrm{Si}$ et al. (2010). Cumming et al. (2008) provide a related study that presents a detailed example of the development of a rudimentary risk map for southern Africa. This analysis is based on expert assessment of the risks associated with particular duck species and environmental variables, together with data on the occurrences of nomadic birds. In another broadscale analysis, McCallum et al. (2008) consider the relevance of biogeography, focusing on "Wallace's line," an area over which there is relatively little bird migration, as a risk factor for AI outbreaks. They present a thorough analysis of uncertainties that relate to connectivity, which in this context is an important aspect of risk. At a finer scale, Caron et al. (2010) explore the dymamic nature of risk; waterbird communities change through the year, and these changes have important implications for the dynamics of avian pathogens. Finally, BrooksMoizer et al. (2009) present an analysis that focuses on one of the interfaces between people and wild birds, looking at the pet trade in markets in Hanoi and the ways in which traders have responded to regulations that were intended to reduce contact between people and wild birds. This study explores some of the poorly understood feedbacks between disease outbreaks and human behaviors.

\section{INFECTIOUS DISEASE IN CONTEXT}

The papers in this special feature are slightly different from "typical" analyses of avian influenza, in that they highlight unknowns rather than knowns. Taken together, they provide a useful summary of some of the things that we know about avian influenza and many of the things that we do not. Looking forward, it seems clear that the future of risk assessment in the context of emerging infectious diseases lies in developing integrative approaches that place the assessment and analysis of infectious disease firmly within a more general context of social-ecological systems. This will mean taking full account not only of variables that are thought to relate directly to human or avian health (for example, see Fauci et al. 2005, Fenton and Pedersen 2005, Hoberg et al. 2008), but also of variables that relate to broader issues like healthrelated institutions and policies, feedbacks and thresholds in human behaviors and ecological regulation of disease, management pathologies, and other relevant characteristics of social-ecological systems (e.g., Holling and Meffe 1996, WaltnerToews et al. 2003, Kaufman 2008).

Although the most obviously "useful" analyses of infectious disease tend to be reductionist and highly mechanistic, many aspects of disease risk and management may be facilitated by looking in more depth at general or emergent system properties (Zinsstag et al. 2009). From a systems perspective, variations in relevant properties of individual social-ecological systems should enhance or reduce their resilience to infectious disease. These properties can be broadly summarized under the categories of structural, spatial, and temporal variables.

Structural variables relating to system resilience to infectious disease include, among other things, local interactions and feedbacks between system components (e.g., Caron et al. 2009, Moleon et al. 2009); the diversity of organisms, social groupings, and/or cultures present in the system (e.g., Agur et al. 1993, Cumming et al. 2005); the nature of the local physical environment, including abiotic variables like climate and water availability (e.g., Johnson et al. 2009); natural, economic, and social capital (Adger 2003); and the capacity of societies to respond to disease outbreaks, which relates closely to wealth and education but also has institutional and organizational components. 
Spatial variation must be considered at multiple scales. At a minimum, it must be assessed internally (locally), externally at the scale of the immediate context (regionally), and externally in relation to relevant global variation (globally). Spatial variables that will influence local resilience to infectious disease include geographic location (Rogers and Randolph 2003), habitat type, location along environmental gradients, connectivity, and system boundaries (e.g., immigration checkpoints or forest edges). The number and nature of connections between system components will determine how rapidly a disease can spread through, for example, a social network, a food web, or a network of cities connected by roads (e.g., Carver et al. 2009).

Temporal variation, like spatial variation, must be considered at a variety of scales ranging from days or weeks through seasons, years, and decades (or longer). Temporal variables that will influence social-ecological resilience to infectious disease are those that relate closely to the location of a system in time, particularly in regard to its past experience (history) and current trajectory. In cases where the rate of pathogen evolution parallels the timing of epidemics, evolutionary and ecological time scales may be the same (Earn et al. 2002). A socialecological system that is entering a winter period with relatively cold, wet weather may be more vulnerable to an influenza epidemic than a system that is currently in summer (Altizer et al. 2006). Similarly, responses to pathogens are influenced by the ghosts of selection past. Prior exposure to related diseases may be an important influence on local resistance and immunity to a particular infection, and growing populations with high proportions of juveniles, whether of humans or other animals, may exhibit different pathogen dynamics from declining or aging populations (e.g., Biek et al. 2006). External perturbations, such as conflict or climate variation, may further alter temporal dynamics and cause changes in the epidemiology of a given disease (Gayer et al. 2007).

One of the central research challenges in this area lies in pulling together a cohesive picture of the interrelationships among different system characteristics. These three basic categories of variables must be integrated into a holistic framework, together with detailed information about such things as transmission mechanisms and variation in immune responses, if they are to result in the rigorous quantification of infectious-disease risks. This is particularly true for some of the more dynamic aspects of social-ecological systems. For example, people will respond in different ways to changes in the prevalence of infectious disease and may, by their reponses, make static models of system properties inaccurate or grossly incorrect. A typical Susceptible-Infected-Recovered (SIR) model or a network-based analysis might assume a certain contact rate between population members (e.g., see Duerr et al. 2007); if people respond to a disease outbreak by staying at home, contact rates will decline, setting in place a negative feedback that may reduce the overall severity of the outbreak relative to predictions. Similarly, policies aimed at disease prevention and control may create winners and losers, and their ultimate success may be determined more by social dynamics than by their scientific soundness (Adger et al. 2005). Societal responses to HPAI and other infectious diseases will clearly need to be cross-sectoral and interdisciplinary.

\section{CONCLUSIONS}

The articles in this special feature present some different ways of approaching the problem of risk mapping for infectious disease, and also serve to highlight ongoing questions and problems in the assessment of disease-related risk. Considerable progress has been made in recent times in understanding the fine-scale mechanisms that underlie outbreaks of avian influenza and other infectious diseases, and in relating these mechanisms to broad-scale patterns. However, the development of a more integrative perspective on infectious disease that better incorporates broader social-ecological dynamics and a more complete assessment of risk remains an important goal for future research in this field.

Responses to this article can be read online at: http://www.ecologyandsociety.org/voll5/iss3/art32/ responses/

\section{Acknowledgments:}

I am grateful to the special feature authors for their contributions to this feature, and to the many colleagues with whom I have discussed these and related ideas. 


\section{LITERATURE CITED}

Adger, W. N. 2003. Social capital, collective action, and adaptation to climate change. Economic Geography 79:387-404.

Adger, W. N., K. Brown, and E. L. Tompkins. 2005. The political economy of cross-scale networks in resource co-management. Ecology and Society 10(2): 9. [online] URL: http://www.ecology andsociety.org/vol10/iss2/art9/.

Adger, W. N., and A. Jordan. 2009. Sustainability: exploring the processes and outcomes of governance. Pages 3-31 inW. N. Adger, and A. Jordan, editors. Governing Sustainability. Cambridge University Press, Cambridge, Massachusetts, USA.

Agur, Z., Y. L. Danon, R. M. Anderson, L. Cojocaru, and R. M. May. 1993. Measles immunization strategies for an epidemiologically heterogeneous population-the Israeli case-study. Proceedings of the Royal Society of London Series B-Biological Sciences 252:81-84.

Altizer, S., A. Dobson, P. Hosseini, P. Hudson, M. Pascual, and P. Rohani. 2006. Seasonality and the dynamics of infectious diseases. Ecology Letters 9:467-484.

Altizer, S., D. Harvell, and E. Friedle. 2003. Rapid evolutionary dynamics and disease threats to biodiversity. Trends in Ecology and Evolution 18:589-596.

Anderson, R. M., and R. M. May. 1983. Vaccination against rubella and measlesquantitative investigations of different policies. Journal of Hygiene 90:259-325.

Bessen, D. E. 2009. Population biology of the human restricted pathogen, Streptococcus pyogenes. Infection Genetics and Evolution 9:581-593.

Beyrer, C. 2007. HIV epidemiology update and transmission factors: risks and risk contextsSixteenth International AIDS Conference Epidemiology Plenary. Clinical Infectious Diseases 44:981-987.

Biek, R., T. K. Ruth, K. M. Murphy, C. R. Anderson, Jr., M. Johnson, R. DeSimone, R. Gray, M. G. Hornocker, C. M. Gillin, and M.
Poss. 2006. Factors associated with pathogen seroprevalence and infection in Rocky Mountain cougars. Journal of Wildlife Diseases 42:606-615.

Borer, E. T., C. E. Mitchell, A. G. Power, and E. W.Seabloom. 2009. Consumers indirectly increase infection risk in grassland food webs. Proceedings of the National Academy of Sciences of the United States of America 106:503-506.

Brooks-Moizer, F., S. I. Roberton, K. Edmunds, and D. Bell. 2009. Avian influenza H5N1 and the wild bird trade in Hanoi, Vietnam. Ecology and Society 14(1): 28. [online] URL: http://www.ecolog yandsociety.org/vol14/iss1/art28/.

Capua, I., and D. J. Alexander. 2002. Avian influenza and human health. Acta Tropica 83:1-6.

Caron, A., N. Gaidet, M. de Garine-Wichatitsky, S. Morand, and E. Z. Cameron. 2009. Evolutionary biology, community ecology and avian influenza research. Infection Genetics and Evolution 9:298-303.

Caron, A., M. De Garine-Wichatitsky, N. Gaidet, N. Chiweshe, and G. S. Cumming. 2010. Estimating dynamic risk factors for pathogen transmission using community-level bird census data at the wildlife/domestic interface. Ecology and Society 15(3): 25. [online] URL: http://www.ecolog yandsociety.org/vol15/iss3/art25/.

Carpenter, S. R. 2002. Ecological futures: building an ecology of the long now. Ecology 83:2069-2083.

Carver, S., A. Bestall, A. Jardine, and R. S. Ostfeld. 2009. Influence of hosts on the ecology of arboviral transmission: potential mechanisms influencing dengue, Murray Valley encephalitis, and Ross River virus in Australia. Vector-Borne and Zoonotic Diseases 9:51-64.

Child, M. F., G. S. Cumming, and T. Amano. 2009. Assessing the broad-scale impact of agriculturally transformed and protected area landscapes on avian taxonomic and functional richness. Biological Conservation 142:2593-2601.

Clark, J. S., S. R. Carpenter, M. Barber, S. Collins, A. Dobson, J. A. Foley, D. M. Lodge, M. Pascual, R. Pielke, W. Pizer, C. Pringle, W. V. 
Reid, K. A. Rose, O. Sala, W. H. Schlesinger, D. H. Wall, and D. Wear. 2001. Ecological forecasts: an emerging imperative. Science 293:657-660.

Cumming, G. S., G. Barnes, S. Perz, M. Schmink, K. E. Sieving, J. Southworth, M. Binford, R. D. Holt, C. Stickler, and T. Van Holt. 2005. An exploratory framework for the empirical measurement of resilience. Ecosystems 8:975-987.

Cumming, G.S.,P.A. R. Hockey, L.W. Bruinzeel, and M. A. Du Plessis. 2008. Wild bird movements and avian influenza risk mapping in southern Africa. Ecology and Society 13(2): 26. [online] URL: http: //www.ecologyandsociety.org/vol13/iss2/art26/.

Daszak, P., A. A. Cunningham, and A. D. Hyatt. 2000. Emerging infectious diseases of wildlife: threats to biodiversity and human health. Science 287:443-449.

Daszak, P., A. A. Cunningham, and A. D. Hyatt. 2001. Anthropogenic environmental change and the emergence of infectious diseases in wildlife. Acta Tropica 78:103-116.

Devendra, C. 2007. Perspectives on animal production systems in Asia. Livestock Science 106:1-18.

Dobson, A., and J. Foufopoulos. 2001. Emerging infectious pathogens of wildlife. Philosophical Transactions of the Royal Society of London Series B-Biological Sciences 356:1001-1012.

Dobson, A., D. Lodge, J. Alder, G. S. Cumming, J. Keymer, J. McGlade, H. Mooney, J. A. Rusak, O. Sala, V. Wolters, D. Wall, R. Winfree, and M. A. Xenopoulos. 2006. Habitat loss, trophic collapse, and the decline of ecosystem services. Ecology 87:1915-1924.

Dudley, J. P. 2008. Public health and epidemiological considerations for avian influenza risk mapping and risk assessment. Ecology and Society 13(2): 21. [online] URL: http://www.ecolog yandsociety.org/vol13/iss2/art21/.

Duerr, H. P., M. Schwehm, C. C. Leary, S. J. De Vlas, and M. Eichner. 2007. The impact of contact structure on infectious disease control: influenza and antiviral agents. Epidemiology and Infection 135:1124-1132.
Dwyer, G., J. S. Elkinton, and J. P. Buonaccorsi. 1997. Host heterogeneity in susceptibility and disease dynamics: tests of a mathematical model. American Naturalist 150:685-707.

Earn, D. J. D., J. Dushoff, and S. A. Levin. 2002. Ecology and evolution of the flu. Trends in Ecology and Evolution 17:334-340.

Fauci, A. S., N. A. Touchette, and G. K. Folkers. 2005. Emerging infectious diseases: a 10-year perspective from the National Institute of Allergy and Infectious Diseases. Emerging Infectious Diseases 11:519-525.

Fenton, A., and A. B. Pedersen. 2005. Community epidemiology framework for classifying disease threats. Emerging Infectious Diseases 11:18151821.

Field, H. E. 2009. Bats and emerging zoonoses: henipaviruses and SARS. Zoonoses and Public Health 56:278-284.

Gayer, M., D. Legros, P. Formenty, and M. A. Connolly. 2007. Conflict and emerging infectious diseases. Emerging Infectious Diseases 13:16251631.

Guernier, V., M. E. Hochberg, and J. F. Guegan. 2004. Ecology drives the worldwide distribution of human diseases. PLoS Biology 2:0740.

Hoberg, E. P., L. Polley, E. J. Jenkins, S. J. Kutz, A. M. Veitch, and B. T. Elkin. 2008. Integrated approaches and empirical models for investigation of parasitic diseases in northern wildlife. Emerging Infectious Diseases 14:10-17.

Holling, C. S., and G. K. Meffe. 1996. Command and control and the pathology of natural-resource management. Conservation Biology 10:328-337.

Jaffry, K. T., S. Ali, A. Rasool, A. Raza, and Z. J. Gill. 2009. Zoonoses. International Journal of Agriculture and Biology 11:217-220.

Johnson, P. T. J., A. R. Ives, R. C. Lathrop, and S. R. Carpenter. 2009. Long-term disease dynamics in lakes: causes and consequences of chytrid infections in Daphnia populations. Ecology 90:132-144. 
Kahn, L. H. 2006. Confronting zoonoses, linking human and veterinary medicine. Emerging Infectious Diseases 12:556-561.

Kaufman, J. A. 2008. China's heath care system and avian influenza preparedness. Journal of Infectious Diseases 197:S7-S13.

McCallum, H. I., D. A. Roshier, J. P. Tracey, L. Joseph, and R. Heinsohn. 2008. Will Wallace's Line save Australia from avian influenza? Ecology and Society 13(2): 41. [online] URL: www.ecology andsociety.org/vol13/iss2/art41/.

Mogollon-Pasapera, E., L. Otvos, A. Giordano, and M. Cassone. 2009. Bartonella: emerging pathogen or emerging awareness? International Journal of Infectious Diseases 13:3-8.

Moleon, M., J. A. Sanchez-Zapata, J. Real, J. A. Garcia-Charton, J. M. Gil-Sanchez, L. Palma, J. Bautista, and P. Bayle. 2009. Large-scale spatiotemporal shifts in the diet of a predator mediated by an emerging infectious disease of its main prey. Journal of Biogeography 36:1502-1515.

Morens, D. M., G. K. Folkers, and A. S. Fauci. 2008. Emerging infections: a perpetual challenge. Lancet Infectious Diseases 8:710-719.

Okes, N. C., P.A. R. Hockey, and G. S. Cumming. 2008. Habitat use and life history as predictors of bird responses to habitat change. Conservation Biology 22:151-162.

Ostfeld, R. S. 2009. Biodiversity loss and the rise of zoonotic pathogens. Clinical Microbiology and Infection 15:40-43.

Peterson, A. T., and R. A. J. Williams. 2008. Risk mapping of highly pathogenic avian influenza distribution and spread. Ecology and Society 13(2): 15. [online] URL: www.ecologyandsociety.org/vol13/ iss2/art15/.

Pontier, D., M. Guiserix, D. Fouchet, F. Sauvage, and J. P. Gonzalez. 2009. Emergence of infectious diseases: when hidden pathogens break out. Comptes Rendus Biologies 332:539-547.

Rogers, D. J., and S. E. Randolph. 2003. Studying the global distribution of infectious diseases using GIS and RS. Nature Reviews Microbiology 1:231237.
Si, Y., T. Wang, A. K. Skidmore, W. F. De Boer, L. Li, and H. H. T. Prins. 2010. Environmental factors influencing the spread of the highly pathogenic avian influenza $\mathrm{H} 5 \mathrm{~N} 1$ virus in wild birds in Europe. Ecology and Society 15(3): 26. [online] URL: http://www.ecologyandsociety.org/vol15/iss3/ art26/.

Stirling, A. C., and I. Scoones. 2009. From risk assessment to knowledge mapping: science, precaution and participation in disease ecology. Ecology and Society 14(2): 14. [online] URL: http: //www.ecologyandsociety.org/vol14/iss2/art14/.

Tatem, A. J. 2009. The worldwide airline network and the dispersal of exotic species: 2007-2010. Ecography 32:94-102.

Tee, K. K., Y. Takebe, and A. Kamarulzaman. 2009. Emerging and re-emerging viruses in Malaysia, 1997-2007. International Journal of Infectious Diseases 13:307-318.

Tilman, D., and C. Lehman. 2001. Human-caused environmental change: impacts on plant diversity and evolution. Proceedings of the National Academy of Sciences of the United States of America 98:5433-5440.

Tung, J., A. Primus, A. J. Bouley, T. F. Severson, S. C. Alberts, and G. A. Wray. 2009. Evolution of a malaria resistance gene in wild primates. Nature 460:388-U103.

Walsh, J. F., D. H. Molyneux, and M. H. Birley. 1993. Deforestation-effects on vector-borne disease. Parasitology 106:S55-S75.

Waltner-Toews, D., J. J. Kay, C. Neudoerffer, and T. Gitau. 2003. Perspective changes everything: managing ecosystems from the inside out. Frontiers in Ecology and the Environment 1:23-30.

Woolhouse, M. E. J., and S. Gowtage-Sequeria. 2005. Host range and emerging and reemerging pathogens. Emerging Infectious Diseases 11:18421847.

Zinsstag, J., E. Schelling, B. Bonfoh, A. R. Fooks, J. Kasymbekov, D. Waltner-Toews, and $M$. Tanner. 2009. Towards a "one health" research and application tool box. Veterinaria Italiana 45:121133. 